\title{
What Are the Economic and Labour Market Effects of an Income Tax Reduction Targeted at Older Workers?
}

\author{
Maxime Fougère, Simon Harvey, and Bruno Rainville \\ Human Resources and Skills Development Canada, 140 Promenade du Portage, Phase 4, 3rd floor, Gatineau, QC, Canada K1A 0J9 \\ Correspondence should be addressed to Maxime Fougère, maxime.fougere@hrsdc-rhdcc.gc.ca
}

Received 29 August 2011; Revised 6 March 2012; Accepted 16 April 2012

Academic Editor: Bernard Fortin

Copyright ( $) 2012$ Maxime Fougère et al. This is an open access article distributed under the Creative Commons Attribution License, which permits unrestricted use, distribution, and reproduction in any medium, provided the original work is properly cited.

\begin{abstract}
This paper explores the economic and labour market effects of implementing a tax reduction targeted at older workers. The analysis is conducted with a life-cycle computable general equilibrium model calibrated on Canadian data. The analysis shows that implementing a permanent income tax reduction for workers aged 60 and over has only small macroeconomic effects because the labour supply increase of older workers is partly offset by a reduction in the labour supply at core ages. This induced effect also discourages savings and generates crowding out through private investment but has a favourable impact on lifetime economic welfare. The macroeconomic impact is much larger when the income tax reduction is temporary because workers no longer reduce their hours at core ages and there is no reduction in savings. However, since only current middle-aged and older workers benefit from the tax cut, a temporary income tax cut reduces intergenerational equity.
\end{abstract}

\section{Introduction}

It is well known that the Canadian population has been ageing steadily for some time as people have been living longer and having fewer children. Compared to most other developed countries, Canada experienced a larger baby boom and a sharper decline in fertility afterward. In the next thirty years, the number of persons aged 65 and older is expected to more than double worldwide. Also, over the past decades, despite the substantial increase in longevity, the trend in early retirement has become widespread. According to Statistics Canada, the average age of retirement has declined steadily in Canada over the period 1976 to 1998 for both men and women, from around 65 for men and 64 for women during the second half of the 1970s to 61.5 years for men and 60 for women in the late 1990s (see Figure 1). Since the bottom reached in 1998, the declining trend in retirement has halted. During the 1999 to 2010 period, the effective retirement age averaged 62.2 and 60.7 for men and women, respectively. It also increased in 2009 and 2010, following the stock market collapse, which led to a decline in the value of pension assets.

Several studies have indicated that population ageing will lead to a significant decline in population and labour force growth, which in turn will reduce economic growth (see, e.g., [1-3]). Early retirement behaviour also raises important public policy challenges because a larger proportion of older workers leaving the labour market would exacerbate the negative economic effects of ageing. Many recent quantitative studies have concluded that public pensions (or social security) in OECD countries have a significant impact on the retirement decisions (see, e.g., $[4,5]$ ). Furthermore, several papers have examined the cost of early retirement or the benefits of working longer. The conventional view from these studies is that the economic benefits of working longer are potentially large. However, these studies for the most part simulate an exogenous increase in retirement age and do not evaluate the effectiveness of policy incentives to encourage older workers to stay longer in the labour market.

Staubli and Zweimuller [6] examine the labour market effect of a major pension reform that was implemented in Austria between 2000 and 2006, which gradually increased the early retirement age by 26 months. (Before the reform, the early retirement age was 60 for men and 55 for women.) They found a decline in retirement of around 20 percentage points among men aged $60-61.5$ and a 7 percentage point increase in employment. For women aged 55-56.5, there was 


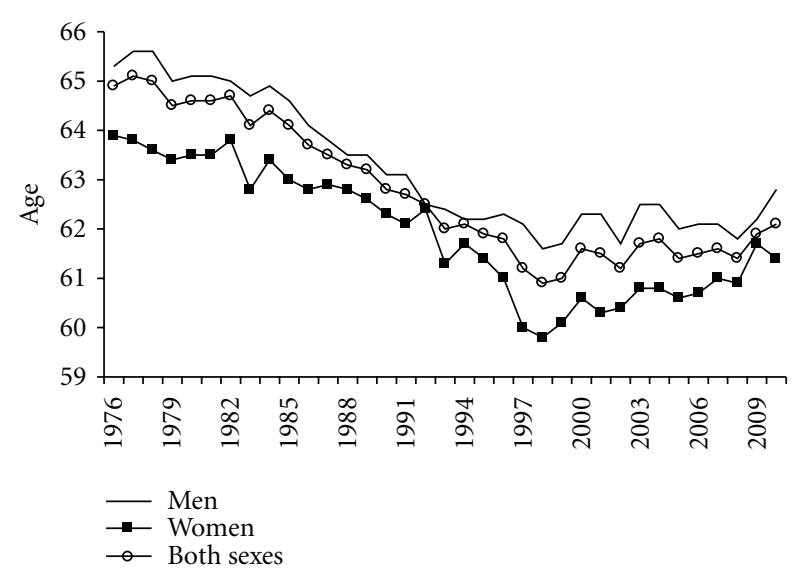

FIGURE 1: Average effective age of retirement in canada by sex, 19762010. Source: Labour Force Survey, Statistics Canada.

a 40 percentage point decline in retirement and a 9 percentage point increase in employment. This increase in labour force participation was also associated with an increase in unemployment as the share of individuals receiving unemployment benefits increased by 10 percentage points for men and 9 percentage points for women.

At the margin, the impact of the reform may seem significant. In aggregate, the economic impact is not necessary large in a country such as Canada in which the public pension system generates few work disincentives compared with other OECD countries [4]. Fougère et al. [7] used a computable general equilibrium (CGE) model to examine the impact of alternative pension reforms that consist of eliminating early retirement incentives and increasing the retirement age in Canada. (In the paper, the simulated option with the largest impact on labour and GDP was to increase the actuarial penalties for taking early retirement benefits of the Canada and Quebec pension plans (C/QPP). By increasing the actuarial penalties for C/QPP benefits before age 65, workers were now on average better off to continue working.) In every case, the policy incentives produced only modest increases (at most one percent) in aggregate labour supply and in economic output.

According to Sheshinski [8], economic agents make suboptimal retirement decisions. Accordingly, policy intervention to reduce early retirement incentives or obstacles to participation in the labour market may be desirable. However, expected small macroeconomic gains associated with alternative public pension policies suggest a need to explore additional avenues, such as encouraging older workers to continue working through tax reforms. For example, Denmark offers a direct tax incentive for older workers. Indeed, a nontaxable income supplement has been granted since 1999 to workers extending their working life beyond age 62 .

This paper's objective is to examine the possible impact on the Canadian economy and the participation rate of older workers of introducing a tax incentive that is similar to the policy introduced in Denmark. The analysis is conducted using a life-cycle computable general equilibrium model calibrated on the Canadian economy. The remainder of the paper is structured as follows. Section 2 summarises the recent literature on the cost of early retirement or benefits of working longer and explains the Danish tax policy incentive. Section 3 describes briefly the model used for the analysis and discusses the simulation exercises. Section 4 reveals the main results obtained and shows the result of incentive scenarios of different magnitude. Section 5 presents some sensitivity tests. The concluding Section 6 discusses some implications for policy.

\section{The Economic Benefits of Working Longer and the Danish Tax Incentive}

Several papers have examined the cost of early retirement or the benefits of working longer. Table 1 presents a summary of selected studies using a variety of methods and indicators including GDP, hours of work, and forgone earnings. Overall, the conventional view from these studies is that the economic benefits of working longer are potentially large. Among the studies, Herbertsson and Orszag [9] estimate that the economic cost of early retirement in terms of unused productive capacity averaged 6.3\% of GDP in 1998 in OECD countries. Hviding and Mérette [10] use a CGE model and estimate that a 4-year increase in retirement age would raise real percapita GDP by 7\% in Canada by 2050. Using a similar method, Fougère et al. [11] find that the marginal effect of a one-year increase in effective retirement age would raise real percapita GDP by $3.2 \%$ by 2050 . Finally, Barrell et al. [12] examine the impact of a one-year increase in the retirement age in UK and found that it would raise real GDP by about 1 percent after six years.

Over the last 10 years, Denmark introduced a series of policy incentives to encourage the extension of older workers' working lives. Denmark changed its taxation plan and its public pension system. First, Denmark changed the voluntary early retirement pension plan (VERP). Major changes included the introduction of a nontaxable premium (staggered over several years) up to $120,000 \mathrm{DK}$ (about $\$ 23,000$ CAN) to people staying in the labour market after age 62 and also a 10\% reduction of the voluntary retirement allowance for those aged 60-62. Secondly, the minimum contribution time and the contribution rate were increased in January 2003 to ensure the lasting quality of the VERP. Admission criteria to the disability pension plan were also tightened. Finally, people aged $65+$ and working more than 1,500 hours annually (about 30 hours weekly) may postpone, since July 2004, the settlement of their pension plan over a 10 -year period. For instance, an individual who postpones his retirement one year would see his pension allowance increased by $7 \%$.

According to Bjørn and Larsen [16] and Jørgensen [17], these tax incentive measures put in place since 1999 have had little impact so far on the participation rate of older workers, despite their increased employment rate noticed since 1997. It can be argued that such policy incentives may take several years before their impact can be perceived on the labour market. 
TABLE 1: Economic impact of a rise in the retirement age (summary of studies).

\begin{tabular}{|c|c|c|c|}
\hline Authors & Approach/Country & Indicator & Summary of results \\
\hline Hviding and Mérette [10] & $\begin{array}{l}\text { CGE model/7 OECD } \\
\text { countries }\end{array}$ & GDP per capita & $\begin{array}{l}\text { 4-year increase in retirement age: increase of } 7 \% \text { by } 2050 \text { for } \\
\text { Canada and } 5.7 \% \text { in the US }\end{array}$ \\
\hline Herbertson and Orszag [9] & Accounting/OECD & GDP & In $1998,6.3 \%$ increase on average in OECD \\
\hline Rowe and Nguyen [13] & $\begin{array}{l}\text { Microsimulation } \\
\text { model } \\
\text { (Lifepaths)/Canada }\end{array}$ & Forgone earnings & $\begin{array}{l}\text { Retirement is delayed to age } 65: \$ 72,000 / \text { household with } \\
\text { normal job loss probability }\end{array}$ \\
\hline Verma and Rix [14] & $\begin{array}{l}\text { Macroeconometric } \\
\text { model of US }\end{array}$ & GDP & LF part. rate of $65+$ returns to 1950: 10\% increase by 2029 \\
\hline Policy Research Initiative [15] & $\begin{array}{l}\text { Microsimulation } \\
\text { model } \\
\text { (Lifepaths)/Canada }\end{array}$ & $\begin{array}{l}\text { Avg. annual hours } \\
\text { per person }\end{array}$ & 3-year extension of working life: 6\% increase in hours by 2025 \\
\hline Fougère et al. [11] & CGE model/ Canada & GDP per capita & $\begin{array}{l}\text { 1-year permanent increase in effective age of retirement: } 3.2 \% \\
\text { increase in GDP per capita by } 2050\end{array}$ \\
\hline Barrell et al. [12] & $\begin{array}{l}\text { Macroeconometric } \\
\text { model }(\mathrm{NiGEM}) / \mathrm{UK}\end{array}$ & GDP & $\begin{array}{l}\text { 1-year permanent increase in effective age of retirement: } 1 \% \\
\text { increase in GDP after } 6 \text { years }\end{array}$ \\
\hline
\end{tabular}

\section{The Model}

3.1. General Description of the Overlapping Generations Model. The analysis uses a life-cycle OLG model of a closed economy. The economy is populated by rational households earning their income by providing their human capital to the production sector and by receiving interest on accumulated assets and transfers. The production sector hires effective labour and rents capital up to their marginal product to produce and sell a single good. The public sector is represented by a national government which levies taxes on consumption and on factors of production and issues oneperiod bonds to finance its spending. The model used in this paper draws on Fougère et al. [3, 18] and Annabi et al. [19].

3.1.1. Household Behaviour. There are 16 overlapping generations of individuals in each 4-year-time period structured in an Allais-Samuelson overlapping generations framework. In each period, a new generation enters the labour market at age 17 and the eldest dies at age 81 . The population growth rate is exogenous. In what follows, the subscript $s$ stands for skill level, $t$ stands for time period and the subscript $g$ stands for the age group.

In each period, the representative agent is endowed with one unit of time which can be allocated towards learning $\left(z_{s, g, t}\right)$, working $\left(\operatorname{LS}_{s, g, t}\right)$, or to leisure activity $\left(\ell_{s, g, t}\right)$. Time allocated to education corresponds to human capital investment effort:

$$
z_{s, g, t}+\mathrm{LS}_{s, g, t}+\ell_{s, g, t}=1
$$

Representative agents maximize an intertemporal utility function with consumption and leisure as arguments subject to two accumulation conditions: wealth and human capital. Earnings are allocated between consumption and savings (domestic physical capital ownership titles and government bonds). Bonds and physical capital are considered perfect substitutes, and thus total supply of assets equals total demand. The agent preferences are represented by an isoelastic time-separable utility function similar to that in Auerbach and Kotlikoff [20] which takes the following form:

$$
U_{s, t}=\sum_{g=1}^{16}\left(\frac{1}{1+\rho}\right)^{g-1} \frac{u\left(C_{s, g, t+g-1}, \ell_{s, g, t+g-1}\right)^{1-\sigma}}{1-\sigma}
$$

where $C_{s, g, t}$ is consumption of an individual of skill level $s$ and age group $g$ at time $t . \rho$ and $\sigma$ are, respectively, the pure rate of time preference and the inverse of the intertemporal elasticity of substitution. The instantaneous preferences are represented by a constant elasticity of substitution (CES) utility function:

$$
u\left(c_{s, g, t}, \ell_{s, g, t}\right)=\left(C_{s, g, t}^{1-\theta}+\phi_{s, g} \ell_{s, g, t}^{1-\theta}\right)^{1 /(1-\theta)}
$$

$\theta$ is the inverse of the intratemporal elasticity of substitution between consumption and leisure, and $\phi_{s, g}$ is the leisure preference parameter.

Human capital evolves according to

$$
\begin{aligned}
h_{s, g+1, t+1}= & \frac{h_{s, g, t}}{1+\delta_{h}}+\beta \cdot h_{s, g, t} \cdot z_{s, g, t}^{\gamma}, \\
& \delta>0, \beta>0,0<\gamma<1,0<\mu<1,
\end{aligned}
$$

where $\delta_{h}$ is the human capital depreciation rate, $\gamma$ represents the elasticity of human capital with respect to the education effort, and $\beta$ is a scale parameter reflecting the efficiency of the education system. 
The accumulation of assets by the representative agent is a function of savings and evolves according to:

$$
\begin{aligned}
\mathrm{FA}_{s, g+1, t+1}-\mathrm{FA}_{s, g, t} \\
=r_{t} \mathrm{FA}_{s, g, t} \cdot\left(1-\tau_{t}^{k}\right) \\
+\left(1-\left(\tau_{s, t}^{w} \cdot \tau_{g, t}^{\mathrm{inc}}\right)-\mathrm{cr}_{t}-\mathrm{dbcr}_{t}\right) \\
\quad \cdot w_{s, t} h_{s, g, t} \mathrm{LS}_{s, g, t}+\left(1-\left(\tau_{s, t}^{w} \cdot \tau_{g, t}^{\mathrm{inc}}\right)\right) \\
\quad\left(\mathrm{Tr}_{s, g, t}+\mathrm{CPP}_{s, g, t}+\mathrm{RPP}_{s, g, t}+\mathrm{OAS}_{s, g, t}\right) \\
+\mathrm{GIS}_{s, g, t}-\left(1+\tau_{t}^{c}\right) \cdot C_{s, g, t},
\end{aligned}
$$

where $\mathrm{FA}_{s, g, t}$ denotes the financial assets accumulated by generation $g$ and skill level $s$ at time $t, \mathrm{Cr}_{t}$ the public pension contribution rate, $\mathrm{dbcr}_{t}$ the defined-benefit registered pension plan (RPP) contribution rate, $w_{s, t}$ the wage rate, and $r_{t}$ the interest rate. $\tau_{s, t}^{w}, \tau_{t}^{k}$, and $\tau_{t}^{c}$ represent, respectively, the effective tax rates on labour income, capital income, and consumption expenditures, and $\tau_{g, t}^{\text {inc }}$ is an employment income tax incentive that differs by age. $\operatorname{Tr}_{s, g, t}$ represents government transfers excluding public pensions, $\mathrm{OAS}_{s, g, t}$ is Old Age Security, GIS $S_{s, g, t}$ includes Guaranteed Income Supplement and Spouse's Allowance (SPA). The Government funds OAS programs (OAS, GIS, and SPA) from general government revenue. $\mathrm{CPP}_{s, g, t}$ is consolidated Canada and Quebec Pension Plans' (CPP/QPP) benefits, and $\mathrm{RPP}_{s, g, t}$ represents the benefits from a defined-benefit RPP. Both CPP/QPP and RPP benefits are a fraction of lifetime best labour earnings and are determined by exogenous pension replacement rates (see Table 2). In (6), total CPP/QPP and RPP benefits equal the total workers' contributions for each respective pension plan. $\mathrm{POP}_{s, g, t}$ represents the number of workers. The contribution rates, $\mathrm{cr}_{t}$ and $\mathrm{dbcr}_{t}$, are endogenously determined to satisfy both equations:

$$
\begin{aligned}
& \sum_{s, g} \mathrm{POP}_{s, g \geq 12, t} \mathrm{CPP}_{s, g \geq 12, t}=\mathrm{cr}_{t} \cdot \sum_{s, g} \mathrm{POP}_{s, g, t} w_{s, t} h_{s, g, t} \mathrm{LS}_{s, g, t}, \\
& \sum_{s, g} \mathrm{POP}_{s, g \geq 10, t} \mathrm{RPP}_{s, g \geq 10, t}=\mathrm{dbcr}_{t} \cdot \sum_{s, g} \mathrm{POP}_{s, g, t} w_{s, t} h_{s, g, t} \mathrm{LS}_{s, g, t} .
\end{aligned}
$$

The optimization problem of the representative agent is to maximize its intertemporal utility (2) subject to the accumulation of human capital (4), to a lifetime version of the budget constraint derived from (5), and to the time constraint described by (1). Optimal consumption and leisure profiles are found by maximizing with respect to $C_{s, g, t}$ and $\ell_{s, g, t}$ (see below), and optimal investment in education is obtained by manipulating the first-order conditions with

\begin{tabular}{|c|c|c|}
\hline Parameter & Notation & Value \\
\hline \multicolumn{3}{|l|}{ Consumer preferences } \\
\hline Intertemporal elasticity of substitution & $1 / \sigma$ & 0.90 \\
\hline Intratemporal elasticity of substitution & $1 / \theta$ & 0.80 \\
\hline \multicolumn{3}{|l|}{ Production technology } \\
\hline Production share of physical capital & $\alpha$ & 0.30 \\
\hline $\begin{array}{l}\text { Elasticity of substitution for labour } \\
\text { demand }\end{array}$ & $\varepsilon$ & 1.50 \\
\hline Depreciation rate of physical capital & $\delta_{k}$ & 0.05 (per year) \\
\hline Interest rate & $r$ & 0.04 (per year) \\
\hline \multicolumn{3}{|l|}{ Human capital technology } \\
\hline Elasticity of time input & $\gamma$ & 0.70 \\
\hline Elasticity of public spending input & $\mu$ & 0.18 \\
\hline \multicolumn{3}{|l|}{ Public policy } \\
\hline $\mathrm{CPP} / \mathrm{QPP}$ replacement rate & PensR & 0.20 \\
\hline $\mathrm{RPP}$ replacement rate & PPensR & $0.02-0.14$ \\
\hline Government expenditures/GDP & & 0.37 \\
\hline Earned income tax rate & $\tau^{w}$ & 0.31 \\
\hline Capital income tax rate & $\tau^{k}$ & 0.38 \\
\hline Consumption tax rate & $\tau^{c}$ & 0.10 \\
\hline
\end{tabular}
respect to $z_{s, g, t}$ and $h_{s, g, t}$. (First-order conditions with respect to $\mathrm{z}_{s, g, t}$ and $h_{s, g, t}$ are not shown, but time allocated to education is positively associated with expected earnings. More time allocated to education (less work) at younger ages increases human capital (4), which in turn raises productivity of workers. The simulation analysis in Section 4 shows
TABLE 2: Behavioural and public policy parameters.

that the impact on expected earnings is small. Therefore, and although not shown, changes on time allocated to education are very small).

Differentiating the utility function with respect to the lifetime budget constraint yields a reservation wage (i.e., implicit price of leisure), $W_{\text {res }}$ for each generation:

$$
\begin{aligned}
W_{\mathrm{res}_{s, g, t}}= & w_{s, t} \cdot h_{s, g, t} \cdot \mathrm{LS}_{s, g, t} \\
& \cdot\left(1-\tau_{s, t}^{w}\right) \cdot\left(1-\mathrm{cr}_{t}-\mathrm{dbcr}_{t}\right)+\mu_{s, g, t},
\end{aligned}
$$

where $\mu_{s, g, t}$ is a Kuhn-Tucker multiplier and differs from zero if and only if the agent chooses to retire in year $t$ and represents the extra money the individual would require to leave retirement and supply labour. The earned income tax rate $\tau_{s, t}^{w}$ is negatively associated with the reservation wage and the presence of $\mathrm{cr}_{t}$ and $\mathrm{dbcr}_{t}$ in the equation means that workers consider CPP/QPP, and RPP contribution rates as marginal tax rates on labour. The intratemporal first-order conditions of the agent problem can be written as

$$
\ell_{s, g, t}=\left[\frac{\phi_{s, g}\left(1+\tau_{t}^{C}\right)}{W_{\text {res }_{s, g, t}}}\right]^{1 / \theta} C_{s, g, t} .
$$

As can be seen in (8), an increase in the reservation wage $W_{\text {res }}$ causes a decline in leisure relative to consumption. In fact, one unit change in the leisure-consumption ratio following a change in the reservation wage is equal to the intratemporal elasticity of substitution $1 / \theta$. Hence, any increase in $\tau^{w}, \mathrm{cr}$, or $\mathrm{dbcr}$ reduces the reservation wage according to (7), which in turn raises leisure activity relative to consumption. 
3.1.2. Producer Behaviour. The production sector is represented by a national firm which hires effective labour $\left(L_{t}\right)$ and rents physical capital $\left(K_{t}\right)$ to produce and sell a single good in a perfectly competitive market. Its production technology is represented by a Cobb-Douglas production function:

$$
Q_{t}=A K_{t}^{\alpha} L_{t}^{1-\alpha}
$$

where $\alpha$ is the share of capital in value added, and $A$ a share parameter. Since adjustment costs in investment are not taken into account, there is no intertemporal optimisation problem for production, and profit maximization requires the equality between marginal productivity and the rate of return of each factor of production:

$$
\begin{gathered}
r_{t}+\delta_{k}=\alpha A K_{t}^{\alpha-1} L_{t}^{1-\alpha} \\
w_{t}=(1-\alpha) A K_{t}^{\alpha} L_{t}^{-\alpha}
\end{gathered}
$$

$r_{t}, w_{t}$, and $\delta_{k}$ denote, respectively, the rate of return to capital, the wage rate and the depreciation rate of physical capital. In addition, labour demand is a composite factor of three skills levels (high-, medium-, and low-skilled workers) represented by a constant elasticity of substitution (CES) function. Consequently, the demand for labour per skill equals

$$
L_{s, t}=A_{s} \cdot\left(\frac{w_{t}}{w_{s, t}}\right)^{\varepsilon} \cdot L_{t},
$$

where $L_{s, t}$ is the effective labour force by skill level $s, w_{s, t}$ the wage rate per skill level, $A_{s}$ a scale parameter, and $\varepsilon$ the elasticity of substitution between skill levels of labour. Given (11), the wage rate per unit of effective labour $w_{t}$ is a function of the wage rate per unit of effective labour of skill level $s$ :

$$
w_{t}=\left(\sum_{s} A_{s} w_{s, t}^{1-\varepsilon}\right)^{1 /(1-\varepsilon)} .
$$

In addition, without adjustment costs, future investments $\left(\operatorname{Inv}_{t}\right)$ are determined by foregone consumption, and the evolution of physical capital stock, financed by borrowing from households, is described by the following law of motion:

$$
K_{t+1}=\left(1-\delta_{k}\right) K_{t}+\operatorname{Inv}_{t}
$$

3.1.3. The Government Sector. The national government issues one-period bonds to finance its spending and the interest on public debt and to satisfy the budget constraint. It levies taxes on labour income, capital income, taxable transfers, and consumption expenditures. It spends on public expenditures $\mathrm{GO}_{t}$, health care $\mathrm{GH}_{g, t}$, education $\mathrm{GE}_{g, t}$, and interest payments on public debt. It also provides transfers to residents through the presence of social transfers. The national government budget constraint is defined as

$$
\begin{aligned}
& \mathrm{GB}_{t+1}-\mathrm{GB}_{t} \\
& =r_{t} \mathrm{~GB}_{t}+\sum_{s, g} \operatorname{Pop}_{s, g, t}\left(\operatorname{Tr}_{s, g, t}+\mathrm{OAS}_{s, g \geq 13, t}+\mathrm{GIS}_{g \geq 13, t}\right) \\
& +\sum_{g}\left(\mathrm{GH}_{g, t}+\mathrm{GE}_{g, t}\right)+\mathrm{GO}_{t} \\
& \quad-\sum_{s, g}\left\{\begin{array}{c}
\operatorname{Pop}_{s, g, t} \cdot\left[\begin{array}{c}
\tau_{s, t}^{w} \cdot\left(w_{s, t} h_{s, g, t} L_{s, g, t}+\operatorname{Tr}_{s, g, t}+\mathrm{OAS}_{s, g \geq 13, t}\right. \\
\left.\left.+\mathrm{CPP}_{s, g \geq 12, t}+\mathrm{RPP}_{s, g \geq 10, t}\right)\right] \\
+\tau_{t}^{c} \cdot C_{g, t}+\tau_{t}^{k} \cdot r_{t} \mathrm{FA}_{s, g, t}
\end{array}\right\} .
\end{array}\right.
\end{aligned}
$$

Equation (14) describes the variation of the stock of public debt $\mathrm{GB}_{t+1}-\mathrm{GB}_{t}$ which is equal to the government deficit. The three remaining expressions on the right-hand side are interest payments on the public debt, total transfer payments ( Tr, OAS, and GIS), which evolve with demographic changes, total expenditures on public services, and government revenues from taxes levied on labour income, public and private pension income, consumption, and returns on assets.

3.1.4. Market Equilibrium Conditions. The model assumes purely competitive markets and perfect foresight agents. It is also assumed that physical capital is entirely detained by local residents and that portfolio choice is subject to home bias with the rest of the world. This is consistent with Helliwell and McTitrick [21] who found evidence that national borders divert flows of savings to domestic investments, but Canadian provincial borders have no such effect. The equilibrium condition for markets of goods states that total output must be equal to total demand:

$$
Q_{t}=\sum_{s, g}\left(\operatorname{Pop}_{s, g, t} C_{s, g, t}\right)+\operatorname{Inv}_{t}+\sum_{g}\left(\mathrm{GH}_{g, t}+\mathrm{GE}_{g, t}\right)+\mathrm{GO}_{t} .
$$

The stock of effective labour supply is the number of workers times their corresponding human capital stock and individual labour supply (i.e., hours):

$$
L_{s, t}=\sum_{g}\left(\operatorname{Pop}_{s, g, t} h_{s, g} \mathrm{LS}_{s, g}\right) .
$$

Bonds and physical capital ownerships are considered perfectly substitutes. Hence, total supply of assets must equal total demand:

$$
\sum_{s, g} \operatorname{Pop}_{s, g, t} \mathrm{FA}_{s, g, t}=K_{t}+\mathrm{GB}_{t} .
$$

\subsection{Calibration of the Model}

3.2.1. Parameterization. Table 2 reports key parameter values for government programs, elasticities, and measures of effective tax rates as calibrated in the model. As shown in 
the table, the value of the intertemporal elasticity of substitution is 0.9 , while the value of the intratemporal elasticity of substitution is 0.8 . These numbers are based on values used in the literature (see, e.g., $[22,23]$ ). The value of the elasticity of substitution for labour demand across qualification is 1.5, which is based on a survey of studies (see [24-27]). The elasticity of time input in the human capital technology is similar to the estimate of Heckman et al. [28] and the value used by Lau [29]. The value for the elasticity of public spending input in human capital is based on the estimation of Blankenau et al. [30]. The production parameters used in the model are also standard in the literature. Finally, the $\mathrm{CPP} / \mathrm{QPP}$ replacement rate is 0.2 , while the $\mathrm{RPP}$ replacement rate is positively associated with age and skill level and ranges between 0.02 and 0.14 . It reflects the fact that the proportion of Canadians who receive benefits from a DB private pension plans increases with age and that average and median benefits from such plans increase with skill levels.

3.2.2. Earning Profiles and Time Allocation over the Life Cycle. Key features of the model calibration are representative skilled workers' life-cycle earnings profiles and time allocated to work, leisure, and education. As presented in Annabi et al. [19], the calibration is based on information from the 2001 Canadian Census and National Occupational Classification (NOC) matrix. Data on time allocated to employment is derived based on the labour force participation rate, while time allocated to human capital formation is derived from the 1998 General Social Survey on Time Use. In the initial steady state, the life-cycle earning profile for high-skilled workers is steeper and higher than medium-skilled and lowskilled workers. In regards to time allocation, representative individuals typically spend a significant proportion of their time to college and university education when young, spend gradually more time in employment as they get older, and decrease their working time in their fifties as their preference for leisure increases. Their working time decreases gradually until they completely withdraw from the labour market when they reach the age of 72 . In the calibration, high-skilled workers spend more time in education when young and more time to work in their core age than medium- and lowskilled workers.

\section{Simulation Exercise}

4.1. Scenarios. The key policy simulation exercise consists of implementing an earned income (i.e., earnings) tax reduction for workers aged 60 and over as of 2006. Two basic simulation exercises are conducted. In Scenario 1, we assume that the tax policy incentive targeted at older workers is permanent, while Scenario 2 assumes that the tax policy change is temporary and effective until 2030.

Also, to maintain budget balance, we assume that the government finances the work incentive by an earned income tax adjustment (i.e., an increase) for taxpayers who are under age 60 . The earned income tax increase is very small because it is distributed amongst a large number of workers under age 60 . The scenarios are compared with a reference scenario

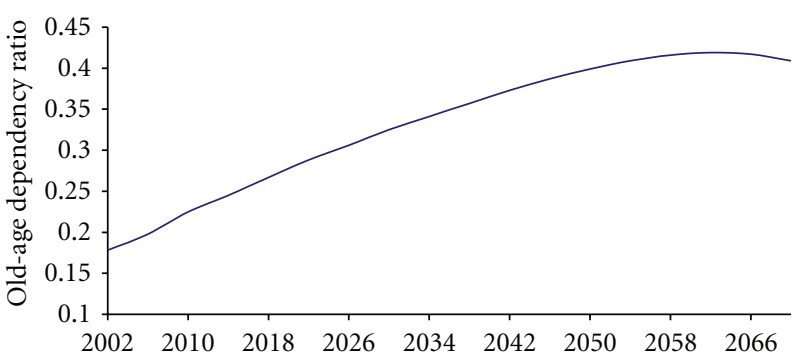

FIGURE 2: Simulated projected population ageing.

which factors in the effect of population ageing. That is, the age structure of the population in the model replicates historical and projected values of the old-age dependency ratio. As shown in Figure 2, the old-age dependency ratio is expected to roughly double from 2010 to 2050 .

4.2. Expected Impact on Labour Supply of an Earned Income Tax Reduction for Older Workers. The objective of the paper is to examine whether reducing earned income taxes for workers aged 60 has a significant impact on aggregate labour supply. In the model, a decrease in earned income tax for older workers increases their incentives to work by raising the implicit price of leisure (see (7) and (8)). However, this tax reduction is financed by a small increase in the earned income tax rate for core-age workers, which may decrease their work effort. Therefore, the net impact on aggregate labour supply is ambiguous and depends on the magnitude of the tax incentive, its financing, and individual's preference for leisure.

4.3. Impact of a Permanent 10 Percent Employment Income Tax Reduction to Older Workers. To understand the labour market effects of a permanent 10 percent employment income tax reduction over the life cycle, Figure 3 shows the effect on weekly working hours for highly skilled (HS) cohorts who joined the labour market in 1982 and 2006. These two cohorts are chosen to explore the impact on workers aged 40 and over (the 1982 cohort), when the policy change is implemented and the cohort of younger workers (the 2006 cohort) have the whole career to adjust their time allocation.

The results show that workers aged 60 and over increase their time allocated to work. For the 1982 cohort, gains are a little more than 0.6 hour on average per week while the 2006 cohort gains are close to 1.0 hour per week. However, those gains are somewhat offset by reduced labour supply from middle-aged workers. Since the tax policy change is permanent, both cohorts choose to allocate more time to leisure activities when young as they anticipate it will be more profitable to work more when they reach the age of 60 (a substitution effect). The effect is less marked for the 1982 cohort than the 2006 cohort, since the 1982 cohort workers have less time to adjust their worked hours following the introduction of the work incentive (they already have 20 years of career when the incentive is introduced in 2006). The impact for medium and low-skilled workers (not represented in 
TABLE 3: Impact of a 10\% permanent reduction in earned income taxes for workers aged 60 and over on key macroeconomic indicators (percentage point difference relative to reference scenario).

\begin{tabular}{|c|c|c|c|c|c|c|}
\hline & 2010 & 2014 & 2022 & 2030 & 2042 & 2050 \\
\hline Real GDP per capita & 0.08 & 0.05 & 0.05 & 0.05 & 0.08 & 0.10 \\
\hline Labour supply/capita & 0.13 & 0.12 & 0.15 & 0.18 & 0.25 & 0.30 \\
\hline National savings & -0.29 & 0.07 & -0.10 & -0.14 & -0.29 & -0.25 \\
\hline Capital stock/capita & -0.05 & -0.13 & -0.19 & -0.32 & -0.42 & -0.47 \\
\hline Capital/labour ratio & -0.19 & -0.28 & -0.38 & -0.57 & -0.79 & -0.93 \\
\hline Real wages & -0.05 & -0.08 & -0.11 & -0.15 & -0.20 & -0.24 \\
\hline Earned income tax rate & -0.13 & -0.13 & -0.13 & -0.13 & -0.13 & -0.14 \\
\hline
\end{tabular}

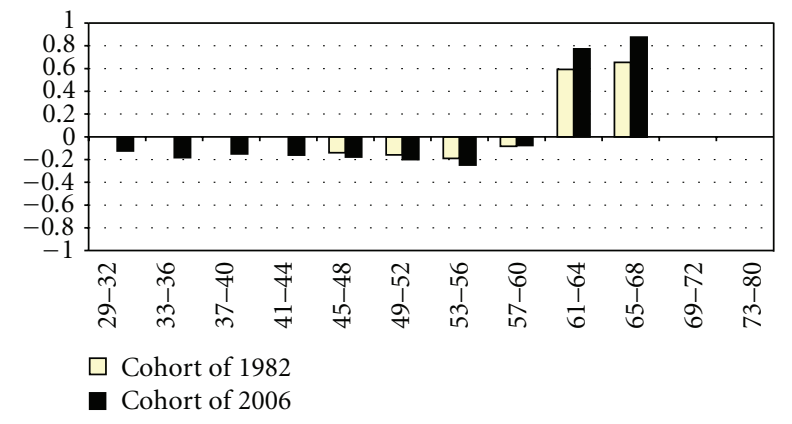

FIGURE 3: Difference in weekly working hours of 1982 and 2006 high-skilled cohorts, permanent $10 \%$ earned income tax reduction. (Difference compared with the reference scenario.)

the graphic) is similar to the impact for high-skilled workers for both cohorts.

Table 3 shows the impact of a $10 \%$ reduction in earned income taxes for workers aged 60 and over on key macroeconomic indicators. As shown in the results, labour supply per capita increases by 0.18 percentage point (p.p.) in 2030 and 0.30 p.p. in 2050 . This implies that the increase in the labour supply of older workers has a net positive impact on aggregate labour supply and more than offsets the reduction in the labour supply of younger workers. Despite this, the gains in real GDP per capita remain very small, a 0.05 p.p. and 0.10 p.p. increase in 2030 and 2050, respectively. This is explained by an effect of crowding out from private savings and investment. The physical capital stock and savings are both lower in the long term, which reduces the gains in real GDP per capita. By reducing time allocated to work, workers aged less than 60 earn less labour income accumulate less saving and thus contribute to a reduction in the accumulated stock of physical capital. In fact, the physical capital intensity (capital/labour ratio) decreases with a lower capital stock and higher labour supply.

The aggregate labour supply increase also contributes to a modest reduction in real wage rates but increases the labour income tax base for the government. Thus, the earned income tax rate can be slightly reduced in aggregate to maintain budget balance, despite the tax reduction for older workers (redistribution of the tax burden).

Similar to Auerbach and Kotlikoff [20] and more recently to Fougère et al. [18], we calculate the level of utility $U_{s, t}$,

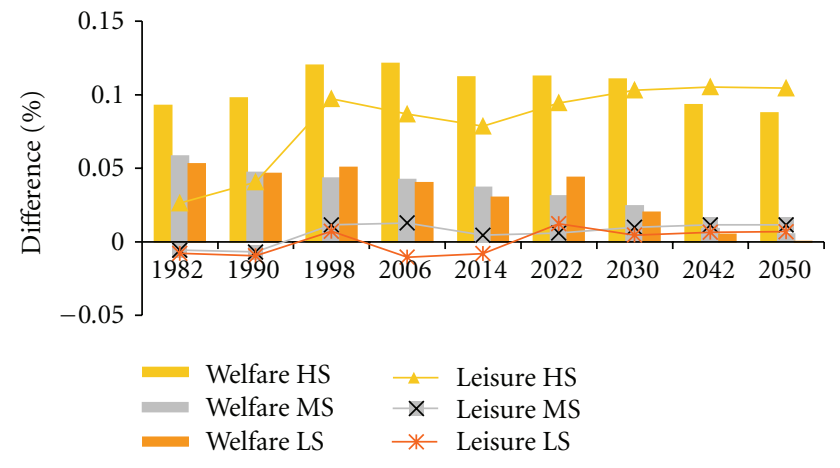

FIGURE 4: Impact of a $10 \%$ permanent reduction in earned income taxes for workers aged 60 and over on economic welfare and leisure over the life cycle per cohort.

which depends on both lifetime consumption and leisure activities (see (1)), by cohort and level of qualification. A cohort is defined by its year of entry in the labour market at 17 years old. Lifetime utility levels, and their lifetime leisure activity part, are calculated by cohort and level of qualification for Scenario $1\left(U_{s, t}^{s 1}\right)$ and the reference scenario $\left(U_{s, t}{ }^{\text {ref }}\right)$. We report the percentage difference $\left(U_{s, t}{ }^{s 1}-U_{s, t}{ }^{\text {ref }}\right) / U_{s, t}$ ref in Figure 4. Despite a decline in time allocated to leisure by workers aged 60 and over (given the increase in hours worked), the increase in leisure time of middle-aged workers (40 to 59) contributes to the overall gain in economic welfare. Economic welfare increases even further for later cohorts (those entering the labour market after 2006), since, following the work incentive, they can change their time allocation over their entire life cycle. For medium- and low-skilled workers, the increase in life-time economic welfare is caused by a rise in life-time consumption as life-time leisure does not change by much. Finally, high-skilled workers benefit more than medium- and low-skilled workers. They can also raise leisure activities because of the beneficial effect of higher income.

4.4. Impact of a More Generous Permanent Tax Cut. Table 4 presents the impact on key macroeconomic indicators of reductions of $10 \%, 20 \%, 30 \%$, and $40 \%$ in earned income taxes for workers aged 60 and over. A more generous tax reduction increases total labour supply, and the increase in 
TABLE 4: Simulated impact of a permanent $10 \%$ to $40 \%$ tax reduction for workers aged $60+$ (percentage point difference relative to the benchmark scenario).

\begin{tabular}{lcccccccc}
\hline & \multicolumn{2}{c}{ Labour supply per capita } & \multicolumn{2}{c}{ National savings } & \multicolumn{2}{c}{ Capital stock per capita } & \multicolumn{2}{c}{ Real GDP per capita } \\
& 2030 & 2050 & 2030 & 2050 & 2030 & 2050 & 2030 \\
\hline $10 \%$ & 0.18 & 0.30 & -0.14 & -0.25 & -0.32 & -0.47 & 0.05 & 2050 \\
$20 \%$ & 0.36 & 0.57 & -0.39 & -0.48 & -0.55 & -0.93 & 0.12 \\
$30 \%$ & 0.54 & 0.85 & -0.62 & -0.75 & -0.81 & -1.41 & 0.19 \\
$40 \%$ & 0.71 & 1.11 & -0.86 & -1.02 & -1.09 & -1.91 & 0.19 \\
\hline
\end{tabular}

real GDP is maximized with a $40 \%$ tax reduction. A greater tax cut does not increase real GDP per capita further in the long run (results not shown) because there is more crowding out from private investment and the negative impact on savings and accumulated physical capital more than offsets additional gains from labour supply on real GDP.

Results also show that a more generous incentive raises economic welfare more because of increased leisure activities of middle-aged workers (not shown here). In short, a greater tax reduction increases economic welfare, but the decrease in savings and accumulated physical capital is also larger and reduces the gains in real GDP per capita.

4.5. Impact of a Temporary 10 Percent Earned Income Tax Reduction to Older Workers. As indicated earlier, when the earned income tax reduction is permanent, younger cohorts choose to reduce their work effort at core ages as they find it more profitable to work more at older ages (they adjust their time allocation decision over their lifetime). Accordingly, the reduction in work effort during core ages lowers the overall impact on total labour supply. In this context, since the rise in the elderly dependency ratio due to ageing is projected to accelerate during the 2010-2030 period and to slow thereafter, it may be argued that the tax cut should be temporary rather than permanent and be implemented during the period when ageing is expected to be most severe. Moreover, a temporary tax cut during the 2010-2030 period would mainly benefit core-age and older individuals. It would have little influence on younger cohorts because they are not expected to receive the benefit at older age.

Figure 5 shows the impact of a temporary 10 percent earned income tax cut, implemented until 2030, on time allocated to work for cohorts who enter the labour market in 1982 and 2006, respectively. As can be seen, the reduction in labour supply for the 2006 cohort during core ages is very small compared with the previous scenario. Under the temporary earned income tax cut scenario, cohorts who enter the labour market in 2006 and younger ones will not benefit from the tax cut at age 60 and over. Therefore, they have no incentive to reduce their work hours when young. The situation is different for older cohorts. Those who entered the labour market in 1982 and older cohorts will benefit from the tax cut at age 60 and over but have a shorter window of opportunity to reduce their work effort at younger age.

Table 5 shows the macroeconomic impact of the temporary tax cut on key economic indicators. As can be seen, there is a larger overall positive impact on real GDP per capita. By 2030, the real GDP per capita gain is more than 4 times larger

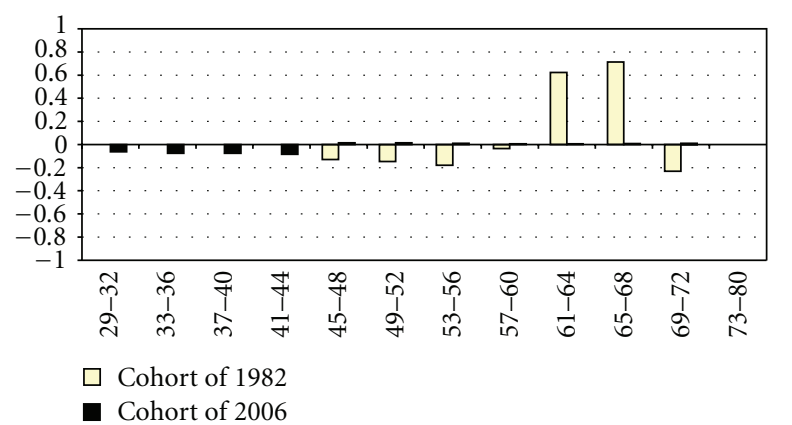

FIGURE 5: Difference in weekly working hours of 1982 and 2006 high-skilled cohorts, temporary $10 \%$ earned income tax reduction. (Difference compared with the reference scenario.)

than with the permanent tax cut scenario, 0.20 p.p. compared with 0.05 p.p. Even after 2030, there are still some positive GDP gains remaining.

There are two key factors at play here that change the results from Scenario 1. First, since the employment income tax cut is temporary, younger cohorts do not reduce their work hours at core ages. Therefore, the total labour supply effect is larger because the increase in older workers' labour supply is partly compensated by very little reduction in younger worker's labour supply. Second, there is no reduction in savings from younger cohorts because they do not plan to work longer. In aggregate, national savings increase rather than decrease and there is no crowding out coming from private investment. Therefore, the negative impact on the physical capital stock per capita and the capital-labour ratio is much smaller and the net real GDP impact remains positive after 2030 .

The policy shock generates some marginal reduction in intergenerational equity although the macroeconomic impact of a temporary earned income tax cut is more favourable for real GDP than a permanent tax cut. Figure 6 presents the lifetime economic welfare impact of a temporary 10 percent tax cut. Not surprisingly, current older generations benefit slightly from the tax cut mainly through increases in lifetime consumption. Future cohorts, however, receive no tax benefit and do not enjoy economic welfare gains.

4.6. Impact of a More Generous Temporary Tax Cut. Just like in Section 4.4, Table 6 presents the impact on key macroeconomic indicators of temporary reductions of $10 \%, 20 \%$, 
TABLE 5: Impact of a 10\% temporary reduction in earned income taxes for workers aged 60 and over on key macroeconomic indicators (percentage point difference relative to reference scenario).

\begin{tabular}{lcccccc}
\hline & 2010 & 2014 & 2022 & 2030 & 2042 & 2050 \\
\hline Real GDP per capita & 0.08 & 0.08 & 0.12 & 0.20 & 0.10 & 0.07 \\
Labour supply/capita & 0.12 & 0.14 & 0.16 & 0.19 & 0.21 & 0.05 \\
National savings & -0.19 & 0.17 & 0.01 & 0.08 & 0.03 & 0.17 \\
Capital stock/capita & -0.03 & -0.07 & -0.19 & -0.21 & 0.15 \\
Capital/labour ratio & -0.16 & -0.24 & -0.05 & 0.16 \\
Real wages & -0.05 & -0.07 & -0.14 & -0.15 & 0.02 & -0.02 \\
Earned income tax rate & -0.13 & -0.14 & & -0.01 \\
\hline
\end{tabular}

TABLE 6: Simulated impact of a temporary 10\% to $40 \%$ tax reduction for workers aged $60+$ (percentage point difference relative to the benchmark scenario).

\begin{tabular}{lcccccccc}
\hline & Labour supply per capita & \multicolumn{2}{c}{ National savings } & \multicolumn{2}{c}{ Capital stock per capita } & \multicolumn{2}{c}{ Real GDP per capita } \\
& 2030 & 2050 & 2030 & 2050 & 2030 & 2050 & 2030 & 2050 \\
\hline $10 \%$ & 0.24 & 0.05 & 0.21 & 0.15 & 0.08 & 0.16 & 0.20 & 0.07 \\
$20 \%$ & 0.46 & 0.09 & 0.42 & 0.31 & 0.16 & 0.31 & 0.39 \\
$30 \%$ & 0.68 & 0.14 & 0.61 & 0.47 & 0.24 & 0.46 & 0.56 & 0.22 \\
$40 \%$ & 0.88 & 0.19 & 0.80 & 0.65 & 0.30 & 0.60 & 0.73 & 0.30 \\
\hline
\end{tabular}

TABLE 7: Impact of a 10\% permanent and temporary reduction in earned income taxes for workers aged 60 and over with a lower intratemporal elasticity of substitution key macroeconomic indicators*.

\begin{tabular}{|c|c|c|c|c|c|c|}
\hline \multirow{2}{*}{ Macroeconomic indicators } & \multicolumn{3}{|c|}{ Permanent } & \multicolumn{3}{|c|}{ Temporary } \\
\hline & 2010 & 2030 & 2050 & 2010 & 2030 & 2050 \\
\hline Real GDP per capita & $0.05(-0.03)$ & $0.05(0.00)$ & $0.05(-0.05)$ & $0.08(0.00)$ & $0.17(-0.03)$ & $0.08(0.01)$ \\
\hline Labour supply/capita & $0.10(-0.03)$ & $0.17(-0.01)$ & $0.25(-0.05)$ & $0.13(0.01)$ & $0.22(-0.02)$ & $0.06(0.01)$ \\
\hline National savings & $-0.27(0.02)$ & $-0.15(-0.01)$ & $-0.24(0.01)$ & $-0.20(0.01)$ & $0.36(0.15)$ & $0.18(0.03)$ \\
\hline Capital stock/capita & $-0.06(-0.01)$ & $-0.30(0.02)$ & $-0.55(-0.08)$ & $-0.03(0.00)$ & $0.00(-0.08)$ & $0.14(-0.02)$ \\
\hline Capital/labour ratio & $-0.16(0.03)$ & $-0.54(0.03)$ & $-0.95(-0.02)$ & $-0.17(-0.01)$ & $-0.29(-0.08)$ & $0.08(-0.03)$ \\
\hline Real wages & $-0.05(0.00)$ & $-0.14(0.01)$ & $-0.24(0.00)$ & $-0.05(0.00)$ & $-0.08(-0.02)$ & $0.02(-0.01)$ \\
\hline Earned income tax rate & $-0.14(-0.01)$ & $-0.14(-0.01)$ & $-0.13(0.00)$ & $-0.15(-0.02)$ & $-0.16(-0.01)$ & $-0.01(0.00)$ \\
\hline
\end{tabular}

${ }^{*}$ Percentage point difference against the reference scenario. Values in brackets are differences compared with the first scenario. See Tables 3 and 5 . The substitution elasticity between consumption and leisure in the general equilibrium model is reduced from 0.8 to 0.6 .

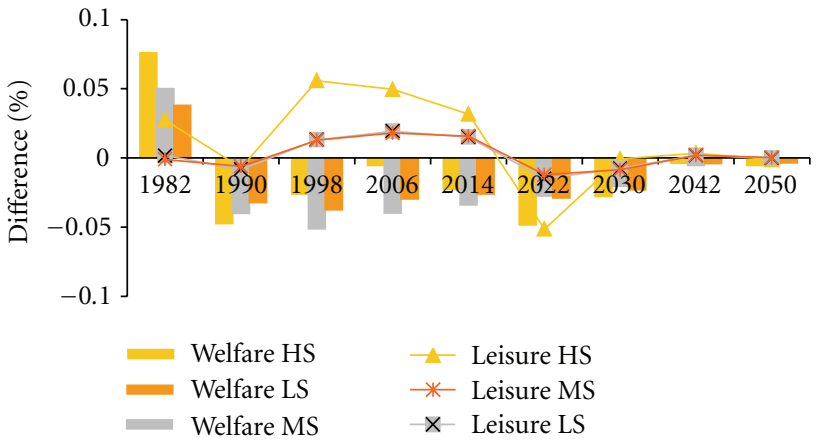

Figure 6: Impact of a 10\% temporary reduction in earned income taxes for workers aged 60 and over on economic welfare and leisure over the life cycle per cohort.

$30 \%$, and $40 \%$ in earned income taxes for workers aged 60 and over. A greater temporary earned income tax cut leads to more labour supply increases at a pace virtually proportional to the change in the tax rate. There is also no crowding out coming from private investment with a larger tax cut. Finally, the real GDP gain is much superior in 2030 and even 2050 compared with implementing a permanent tax cut. For example, a $40 \%$ earned income tax cut would raise real GDP per capita by 0.73 p.p. in 2030 and still 0.30 p.p. in 2050, even though the tax cut has been removed; thanks to the positive capital stock accumulation effect.

\section{Sensitivity Tests}

To verify the robustness of the results, several sensitivity tests have been performed. For the type of shock performed here, the results can be sensitive to two key parameters. The first is the intratemporal elasticity of substitution, which measures the degree to which workers are willing to substitute consumption for leisure or inclined to change their working hours when the return to work varies. The second key parameter is the intertemporal elasticity of substitution, which 
TABLE 8: Impact of a 10\% permanent and temporary reduction in earned income taxes for workers aged 60 and over when the intertemporal rate of substitution increased, key macroeconomic indicators*.

\begin{tabular}{|c|c|c|c|c|c|c|}
\hline \multirow{2}{*}{ Macroeconomic indicators } & \multicolumn{3}{|c|}{ Permanent } & \multicolumn{3}{|c|}{ Temporary } \\
\hline & 2010 & 2030 & 2050 & 2010 & 2030 & 2050 \\
\hline Real GDP per capita & $0.06(-0.02)$ & $0.06(0.01)$ & $0.10(0.00)$ & $0.09(0.01)$ & $0.19(0.01)$ & $0.07(0.00)$ \\
\hline Labour supply/capita & $0.11(-0.02)$ & $0.18(0.00)$ & $0.29(0.01)$ & $0.13(0.01)$ & $0.24(0.00)$ & $0.04(-0.01)$ \\
\hline National savings & $-0.25(0.04)$ & $-0.20(-0.06)$ & $-0.23(0.02)$ & $-0.19(0.00)$ & $0.25(0.04)$ & $0.16(0.01)$ \\
\hline Capital stock/capita & $-0.06(-0.01)$ & $-0.29(0.03)$ & $-0.47(0.00)$ & $-0.03(0.00)$ & $0.05(-0.03)$ & $0.15(-0.01)$ \\
\hline Capital/labour ratio & $-0.18(0.01)$ & $-0.54(0.03)$ & $-0.92(0.01)$ & $-0.18(-0.02)$ & $-0.25(-0.04)$ & $0.11(0.00)$ \\
\hline Real wages & $-0.05(0.00)$ & $-0.14(0.01)$ & $-0.24(0.00)$ & $-0.05(0.00)$ & $-0.07(-0.01)$ & $0.03(0.00)$ \\
\hline Earned income tax rate & $-0.13(0.00)$ & $-0.13(0.00)$ & $-0.14(0.00)$ & $-0.13(0.00)$ & $-0.15(0.00)$ & $-0.01(0.00)$ \\
\hline
\end{tabular}

${ }^{*}$ Percentage point difference against the reference scenario. Values in brackets are differences compared to the first scenario. See Tables 3 and 5 . The intertemporal rate of substitution in the general equilibrium model is increased from 0.9 to 1.1 .

TABLE 9: Impact of a 10\% permanent and temporary reduction in earned income taxes for workers aged 60 funded through a lump-sum tax, key macroeconomic indicators*.

\begin{tabular}{|c|c|c|c|c|c|c|}
\hline \multirow{2}{*}{ Macroeconomic indicators } & \multicolumn{3}{|c|}{ Permanent } & \multicolumn{3}{|c|}{ Temporary } \\
\hline & 2010 & 2030 & 2050 & 2010 & 2030 & 2050 \\
\hline Real GDP per capita & $0.17(0.09)$ & $0.19(0.14)$ & $0.21(0.11)$ & $0.18(0.10)$ & $0.36(0.16)$ & $0.09(0.02)$ \\
\hline Labour supply/capita & $0.27(0.14)$ & $0.34(0.16)$ & $0.42(0.12)$ & $0.27(0.15)$ & $0.41(0.17)$ & $0.06(0.01)$ \\
\hline National savings & $-0.24(-0.05)$ & $0.16(0.31)$ & $-0.23(0.02)$ & $-0.27(-0.08)$ & $0.18(-0.03)$ & $0.15(0.00)$ \\
\hline Capital stock/capita & $-0.03(-0.02)$ & $-0.17(0.15)$ & $-0.41(0.06)$ & $-0.06(-0.03)$ & $0.20(0.12)$ & $0.21(0.05)$ \\
\hline Capital/labour ratio & $-0.33(-0.17)$ & $-0.32(-0.11)$ & $-0.01(-0.10)$ & $-0.35(-0.19)$ & $-0.30(-0.09)$ & $0.09(0.03)$ \\
\hline Real wages & $-0.10(-0.05)$ & $-0.11(-0.03)$ & $-0.14(-0.03)$ & $-0.10(-0.05)$ & $-0.04(-0.02)$ & $0.04(0.01)$ \\
\hline
\end{tabular}

${ }^{*}$ Percentage point difference against the reference scenario. Values in brackets are differences compared to the scenarios in which the tax reduction is financed through increases in the earned income tax rate for worker under the age of 60 .

measures the degree to which workers are willing to substitute current consumption with future consumption, which depends on changes in the return to savings. As a third sensitivity analysis, we have also simulated permanent and temporary tax incentives that are financed through a lumpsum tax instead of an earned income tax. The lump-sum tax paid by each representative individual is proportional to its demographic weight in the whole population.

Table 7 presents the effects of a permanent and temporary 10 percent income tax reduction for workers aged 60 and over using an intratemporal elasticity of substitution of 0.6 as opposed to 0.8 in the original simulation, assuming that workers here are less willing to change their working hours following a tax cut. This corresponds to a 25 percent reduction in the substitution elasticity parameter. Overall, the results change very little (the difference with respect to the original results is in brackets). The impact of the shock on labour supply per capita is somewhat weaker initially, thus having to a smaller impact on real GDP per capita, physical capital stock, and national savings. This leaves a stronger message that the macroeconomic impact of such policy is expected to be small. The conclusion does not change when applying a temporary tax cut. The main difference here is that national savings increase a little more with a lower intratemporal elasticity of substitution when the shock is temporary as opposed to being permanent.

Table 8 presents the effects of a permanent and temporary 10 percent income tax reduction for workers aged 60 and over using an intertemporal elasticity of substitution of 1.1 as opposed to 0.9 in the original simulation, assuming that workers are more willing to adjust their savings pattern when the return to savings changes, following a tax cut. As can be seen in the table, there is virtually no change in the results.

Finally, Table 9 presents the results of a 10\% labour income tax reduction for workers aged 60 and over which is financed through a lump-sum tax. Overall, financing the tax reduction through a less distortionary lump-sum tax leads to a more positive outcome. There is more labour supply increase and less crowding out through savings and investment, but it also results in a greater reduction in physical capital intensity. Note that the macroeconomic impact remains relatively small.

\section{Conclusion}

Although many studies have demonstrated that the economic and fiscal benefits of working longer are potentially large, the analysis shown here demonstrates that it would be difficult to achieve a significant increase in older workers' labour supply through policy incentives, such as implementing tax reductions for older workers. Another interesting finding is that the magnitude of the impact could significantly vary depending on whether individuals perceive the tax policy reduction as permanent or temporary. 
In our analysis, we assume that over the life cycle, economic agents use all available information in a rational way to maximise their life-time utility and adjust their time allocation between education, work, and leisure. In this context, implementing a permanent tax cut targeted at older workers would have little economic impact since younger workers would modify their time allocation over their working lives, choosing to work and save less when young and to work more when old. In this circumstance, it would be more economically beneficial to implement a tax cut that would be perceived as temporary by younger workers rather than permanent. There are both winners and losers with this policy, since only current middle-aged and older workers would expect to benefit from the tax cut, thus creating some reduction in intergenerational equity.

Finally, the results reinforce the idea that there is no magic bullet or single policy option to consider if we want to have a significant influence on older workers' labour supply. Several other complementary policies need to be considered, such as stimulating productivity as well as incentives for other possible targeted groups or more marginally attached workers.

\section{Acknowledgments}

The authors wish to thank Gilles Bérubé, Jeff Carr, James Davies, Louis Grignon, and two anonymous referees for useful comments on earlier versions of this paper and Nabil Annabi for technical advices. All remaining errors are the authors'. The views expressed in this paper are solely those of the authors and do not necessarily reflect the views of HRSDC nor those of the Government of Canada.

\section{References}

[1] D. E. Bloom, D. Canning, and G. Fink, "Implications of population ageing for economic growth," Oxford Review of Economic Policy, vol. 26, no. 4, pp. 583-612, 2010.

[2] J. Banister, D. E. Bloom, and L. Rosenberg, "Population aging and economic growth in China," PGDA Working 53, 2010.

[3] M. Fougère, S. Harvey, J. Mercenier, and M. Mérette, "Population ageing, time allocation and human capital: a general equilibrium analysis for Canada," Economic Modelling, vol. 26, no. 1, pp. 30-39, 2009.

[4] J. Gruber and D. A. Wise, Social Security and Retirement Around the World, University of Chicago Press, Chicago, Ill, USA, 2004.

[5] J. Alonso Ortiz, "Social security and retirement across the OECD," Job Market Paper Prepared at the Centro de Investigacion Economica, Instituto Tecnologico Autonomo de Mexico, 2011.

[6] S. Staubli and J. Zweimuller, "Does raising the retirement age increase employment of older workers?" IZA Discussion Paper 5863, Institute for the Study of Labor, 2011.

[7] M. Fougère, S. Harvey, Y. Lan, A. Léonard, and B. Rainville, "Incentives for early retirement in Canada's defined-benefit public and private pension plans: an analysis with a dynamic life-cycle CGE model," in Retirement Policy Issues in Canada, John Deutch Institute, 2009.
[8] E. Sheshinski, "Optimum delayed retirement credit," CESifo Working Paper 889, Center for Economic Studies and Ifo Institute for Economic Research, 2003.

[9] T. T. Herbertsson and J. M. Orszag, "The economic cost of early retirement in the OECD," Working Paper 01:02, Institute of Economic Studies, 2001.

[10] K. Hviding and M. Mérette, "Macroeconomic effects of pension reform in the context of ageing : OLG simulations for seven OECD countries," OECD Working Paper 201, Paris, France, 1998.

[11] M. Fougère, S. Harvey, J. Mercenier, and M. Mérette, "Population Ageing and the Effective Age of Retirement in Canada," Skills Research Initiative, Working Paper A-03, 2005.

[12] R. Barrell, S. Kirby, and A. Orazgani, "The macroeconomic impact from extending working lives," Department for Work and Pensions, Working Paper 95.

[13] G. Rowe and H. Nguyen, "Early retirement in perspective: insights from the lifepaths microsimulation model," Report Prepared for Human Resources Development Canada, 2003.

[14] S. Verma and S. Rix, "Retirement age and social security reform: the macroeconomic effects of working longer," Issue Brief 59, Public Policy Institute, 2003.

[15] Policy Research Initiative, "Population aging and life-course flexibility: the pivotal role of increased choice in the retirement decision," Discussion paper prepared for the PRI-SSHRC Roundtable on Life-Course Based Policies, Ottawa, Canada, 2004.

[16] N. H. Bjørn and M. Larsen, Tilbagetraekning Udskydes, vol. 2, Social Forskning, Copenhagen, Denmark, 2003.

[17] M. S. Jørgensen, Danskerne Traekker Sig Senere Tilbage Fra Arbejdsmarkedet, vol. 1, Social Forskning, Copenhagen, Denmark, 2004.

[18] M. Fougère, S. Harvey, and B. Rainville, "Would an increase in high-skilled immigration in Canada benefit workers," Economics Research International, vol. 2011, Article ID 171927, 7 pages, 2011.

[19] N. Annabi, S. Harvey, and Y. Lan, "Public expenditures on education, human capital and growth in Canada: an OLG model analysis," Journal of Policy Modeling, vol. 33, no. 6, pp. 852-865, 2011.

[20] A. J. Auerbach and L. J. Kotlikoff, Dynamic Fiscal Policy, Cambridge University Press, Cambridge, UK, 1987.

[21] J. F. Helliwell and R. McKitrick, "Comparing capital mobility across provincial and national borders," Canadian Journal of Economics, vol. 32, no. 5, pp. 1164-1173, 1999.

[22] D. Altig, A. Auerbach, L. Kotlikoff, K. Smetters, and J. Walliser, "Simulating U.S. tax reform," NBER Working Paper 6246, 1997.

[23] L. Kotlikoff, K. Smetters, and J. Walliser, "Privatizing social security: a simulation study," in Pension System: From Crisis to Reform, K. S. Hebbel, Ed., The World Bank, Washington, DC, USA, 1999.

[24] A. Ciccone and G. Peri, "Long-run substitutability between more and less educated workers: evidence from U.S. states, 1950-1990," Review of Economics and Statistics, vol. 87, no. 4, pp. 652-663, 2005.

[25] P. Krusell, L. E. Ohanian, J. V. Ríos-Rull, and G. L. Violante, "Capital-skill complementarity and inequality: a macroeconomic analysis," Econometrica, vol. 68, no. 5, pp. 1029-1053, 2000.

[26] F. Caselli and W. Coleman, "The world technology frontier," NBER Working Paper 7904, 2000.

[27] L. F. Katz and K. M. Murphy, "Changes in relative wages, 1963-1987: supply and demand factors," Quarterly Journal of Economics, vol. 107, no. 1, pp. 35-78, 1992. 
[28] J. J. Heckman, L. Lochner, and C. Taber, "Explaining rising wage inequality: explorations with a dynamic general equilibrium model of labor earnings with heterogeneous agents," Review of Economic Dynamics, vol. 1, no. 1, pp. 1-58, 1998.

[29] M. I. Lau, "Assessing tax reforms when human capital is endogenous," in Using Dynamic General Equilibrium Models for Policy Analysis, G. Harrison, S. E. H. Jensen, L. H. Pedersen, and T. F. utherford, Eds., North Holland, 2000.

[30] W. F. Blankenau, N. B. Simpson, and M. Tomljanovich, "Public education expenditures, taxation, and growth: linking data to theory," American Economic Review, vol. 97, no. 2, pp. 393 $397,2007$. 


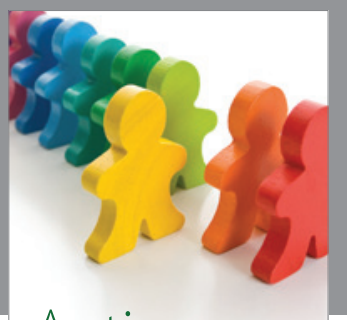

Autism

Research and Treatment
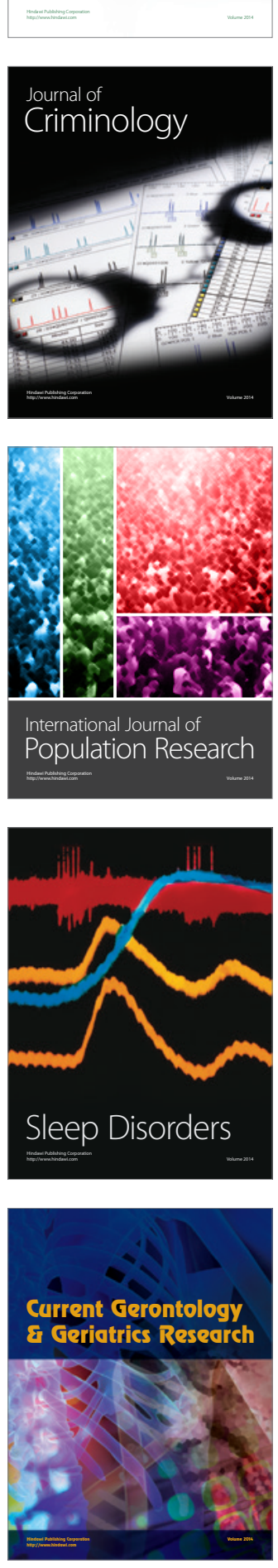
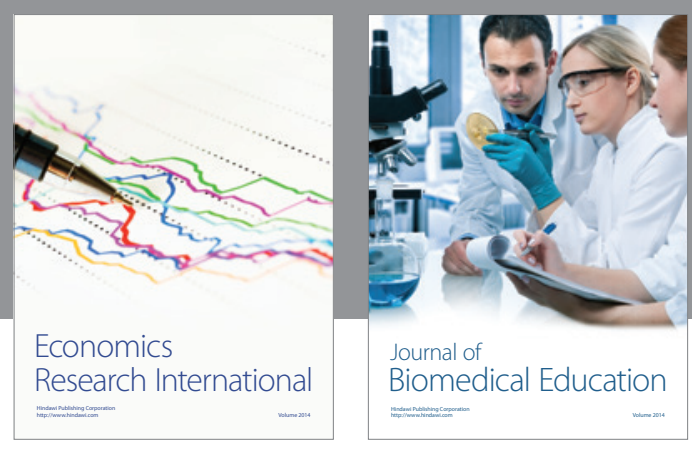

Journal of

Biomedical Education

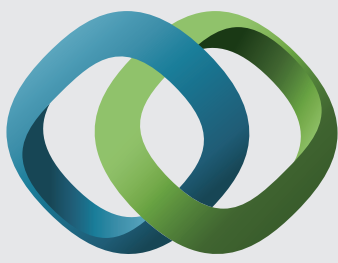

\section{Hindawi}

Submit your manuscripts at

http://www.hindawi.com
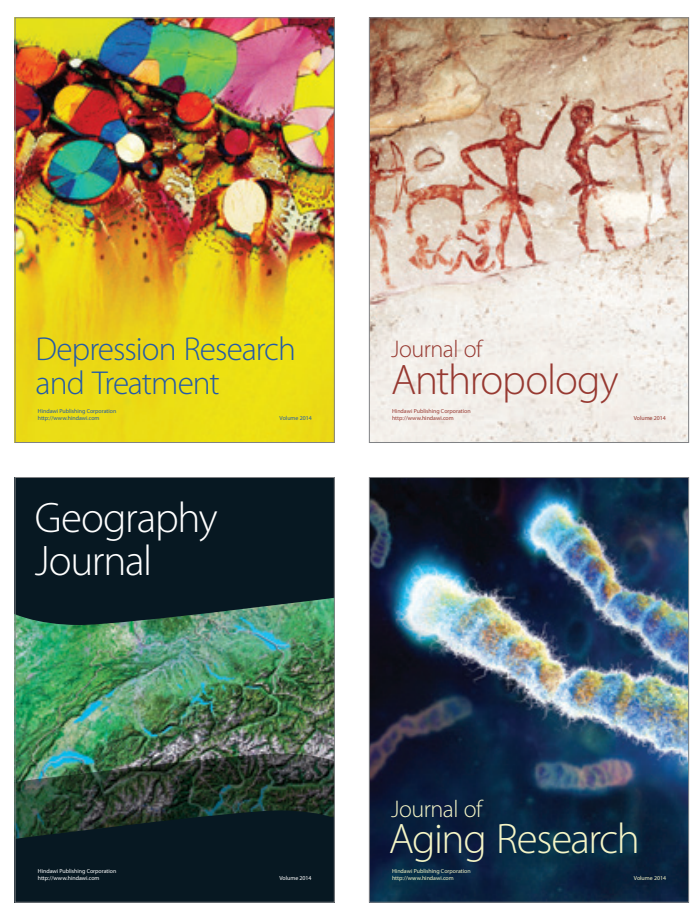

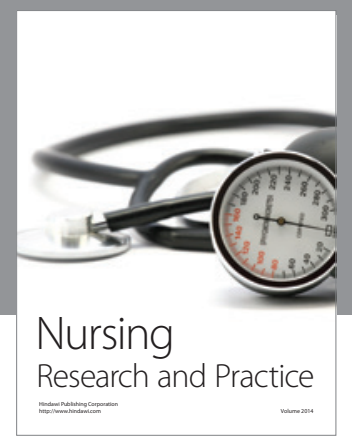

Nursing

Research and Practice

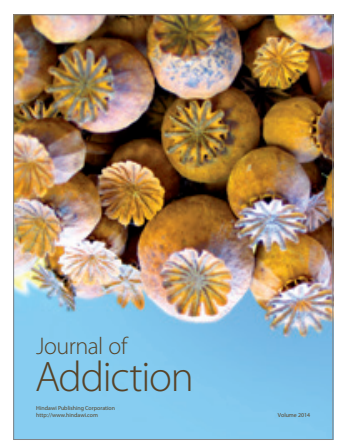

Child Development

Research

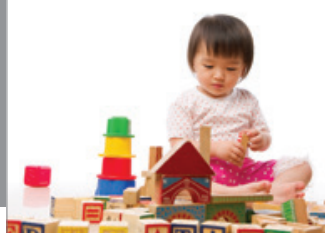

迥
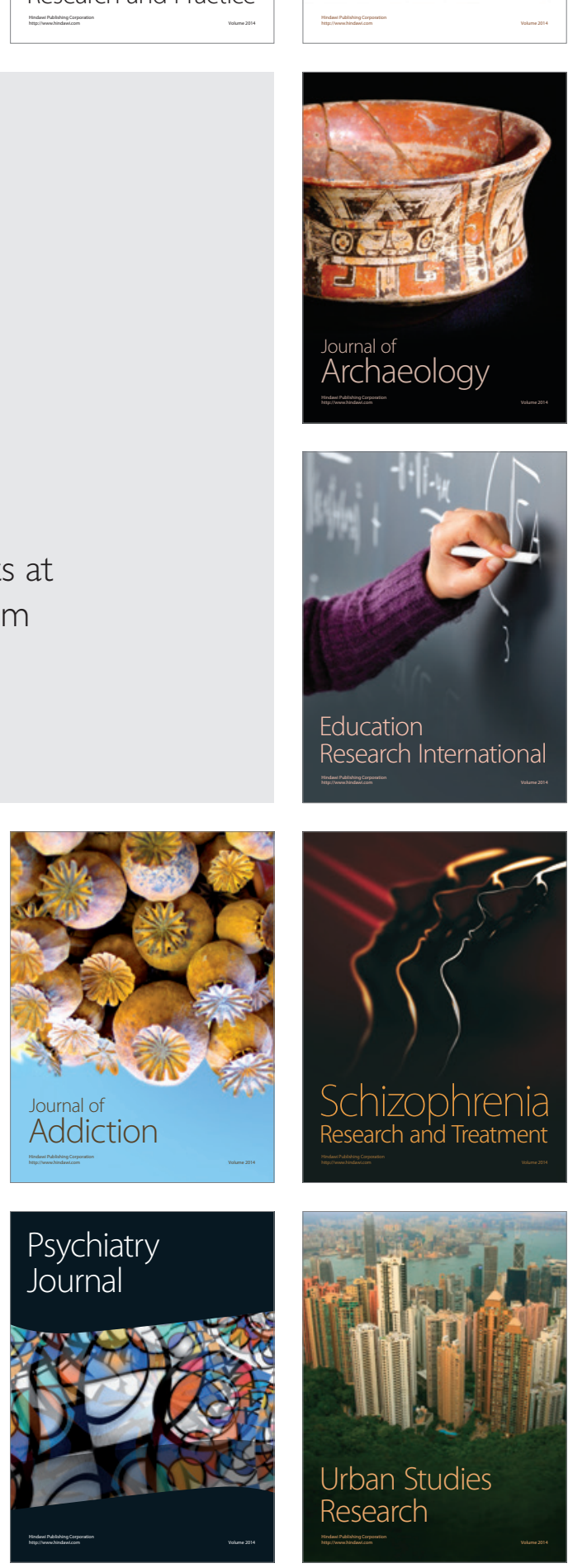